УдК 366.1-053.9

\title{
ПОТЕНЦИАЛ РАЗВИТИЯ ПРАКТИК ПОТРЕБЛЕНИЯ В СТАРШЕМ ВОЗРАСТЕ
}

\author{
Рождественская Елена Михайловна, \\ elena.rojdestvenskaya@gmail.com \\ Национальный исследовательский Томский политехнический университет, \\ Россия, 634050, Томск, пр. Ленина, 30
}

Рождественская Елена Михайловна, кандидат экономических наук, ведущий научный сотрудник Международной научно-образовательной лаборатории технологий улучшения благополучия пожилых людей Национального исследовательского Томского политехнического университета.

\begin{abstract}
Актуальность. Работа обращает внимание на проблемы формирования практик потребления в старшем возрасте как быстрорастущего рыночного сегмента (темп прироста, по данным Всемирного банка, - 3 \% в год). Цель - выявить тенденции изменения потребительского поведения в условиях социальных ограничений и определить доступность новых цифровых социальных сервисов для пожилых людей. Методы: в качестве эмпирической базы используются данные социологических опросов, проведенных в ноябре 2020 2. (N=60) и в марте-апреле 2021 г. $(N=400 ; 55+)$ на территории Томской области. В результате установлено, что низкая потребительная способность влияет на формирование практик потребления. Выявлен институциональный разрыв высоких потребностей в социальных услугах и низкого спроса на созданные социальные сервисы. Выводы: практики потребления в старшем возрасте гетерогенны, значительное влияние оказывают дефицит финансовых ресурсов и ценностные установки помощи ближнему кругу, возникают стратегии экономии на самом необходимом. Субъективная оценка респондентов институтов социальной поддержки крайне низкая. Выявлено, что только в сфере социальной помощи создаются новые практики дистанционного взаимодействия на основе цифровизации сервисов социальных услуг. Практики дистанционного обращения за материальной или медицинской помощью не сформировались. Доверие к институту государственной поддержки крайне низкое, новые цифровые сервисы не оказывают существенного влияния на поддержание уровня и качества жизни в условиях социальных ограничений старшей возрастной группы.
\end{abstract}

Ключевые слова: Активное долголетие, практики потребления, ресурсный потенциал, экономика старения, институциональная экономика, благополучие, социальные институты.

\section{Введение}

В фокусе исследования находится субъективная оценка формирования новых практик потребления и эффективности институтов социальной поддержки в условиях цифровизации экономики и неопределенности, связанной с пандемией и введенными социальными ограничениями [1]. С экономической точки зрения социальные институты являются производителями социальных услуг и в условиях постмодернистского контекста [2] должны фокусироваться на потребностях целевой аудитории, в частности уязвимой старшей возрастной группы предпенсионного и пенсионного возраста. В экономических исследованиях поведение потребителей проявляют реакции на новую социогуманитарную парадигму. Например, подход потребительской культуры, основанный Арноулдом и Томпсоном в 2005 г. [3], представлен как новая революция в научной проблематике в сфере потребления. Утверждается, что индивид ведет себя и потребляет с определенной целью [4] во временных рамках, проживая свои действия как личный опыт или как об- 
щую игру [5]. Следовательно, поведение потребителя нельзя понять без учета всех аспектов его жизни и деятельности [6], таких как идеологическое, социальное, культурное, символическое и эмпирическое потребление в его контексте [2]. Следовательно, производитель продукта, в том числе, социальных услуг вынужден формулировать предложение для целевой аудитории на основе ценностного подхода [7].

Выявлено, что согласно субъективным оценкам старшего поколения существует вытесняющий эффект потребления в связи с расходами на поддержку пожилых людей $[8,9]$. Данные Всемирного банка показывают тенденцию старения населения темпами по $3 \%$ в год [10], что влияет на рост экономики старения, в том числе и в России. Изменения в возрастной структуре происходят из-за сокращения рождаемости и смертности, что приводит к «старению» и повышению нагрузки на пенсионную систему [11]. Если критически оценить, то тут возможны как положительные, так и отрицательные эффекты. Увеличение продолжительности жизни положительно влияет на наращивание трудового потенциала, что ведет к экономическому развитию за счет так называемых «демографических дивидендов» [12]. Но смена образа жизни и потребительского поведения предъявляет новые потребности и вызовы для экономической системы в целом, повышается нагрузка на социальные институты, что приводит к стагнации и неравенству [13]. В старшем возрасте трудовые доходы ниже потребности в особых товарах и услугах, часть этой социальной нагрузки покрывается за счет государственных институтов поддержки, но часть ложится на плечи молодого поколения, снижая потребительский потенциал [14]. Практики потребления представляют собой набор рутинизированных действий в целях удовлетворения потребностей [15]. Цель данной работы - выявить тенденции изменения потребительского поведения в условиях социальных ограничений и определить доступность новых цифровых социальных сервисов для пожилых людей [16] по результатам опросов, проведенных в Томской области.

\section{Методы исследования}

Эмпирической базой исследования являются результаты социологических опросов, проведенных Международной научно-образовательной лабораторией технологий улучшения благополучия пожилых людей Томского политехнического университета в марте-апреле 2021 г. и ноябре 2020 г. Выборка в 2021 г. составила 400 человек, использовались квоты по географическому (50\% - г. Томск, $20 \%$ - город области, $30 \%-$ сельская местность) и демографическому признакам (36 \% - мужчины, $64 \%-$ женщины). Использовались квоты по возрастным группам, соответствующие генеральной совокупности по Томской области. Анкета опроса состояла из 78 вопросов, разделенных по блокам - социально-демографические параметры, уровень материального благополучия, социальное настроение и ожидания, оценка качества предоставления социальных услуг, социальная активность, уровень владения современными технологиями.

В ноябре 2020 г. в Томске было проведено социологическое исследование методом полу-структурированного интервью. В итоге было опрошено 34 работающих респондента и 26 неработающих $(N=60 ; 50+)$. Соотношение мужчин и женщин примерно равное. Сценарий интервью состоял из 10 вопросов по следующим направлениям исследования:

- выявление институциональных возможностей и пробелов государственной поддержки лиц предпенсионного и пенсионного возраста;

- оценка субъективной ценности процесса реализации льгот и гарантий, изучение субъективного отношения к институту социальных льгот и общей осведомленности о льготном пакете; 
- анализ неудовлетворенных потребностей (каких льгот не хватает) и оценка эффектов института «социальный помощник» для людей предпенсионного и пенсионного возраста.

В исследовании предпринята попытка выявить потребительские предпочтения в старшем возрасте в зависимости от покупательной способности. Гипотезой исследования является предпосылка о низкой покупательной способности, вынуждающей применять стратегии экономии в старшем возрасте [16].

\section{Потенциал развития практик потребления в старшем возрасте на примере Томской области}

Количественные данные по Томской области основываются на ежегодных опросах, которые проводятся Международной научно-образовательной лабораторией технологий улучшения благополучия пожилых людей [17] Томского политехнического университета (далее - МНОЛ ТБУПЛ ТПУ). В 2021 г. реализовано исследование на выборке 400 человек в разрезе трех возрастных групп: предпенсионной, пенсионной и старшей пенсионной $(75+)$.

Первоочередная цель опрошенных - возрастная проблема: подлечиться (53 \%), а также отдохнуть, повидаться с родственниками. Наблюдается низкое материальное благополучие. В Томске по сравнению с областью показатели материального положения ниже, более половины респондентов тратят весь доход на продукты питания, что говорит о низком качестве жизни. В сельской местности ситуация обстоит несколько лучше (30 \%). Доминирующая стратегия потребления - экономия, потенциал «серебряного» рынка не развит, хотя в мире наблюдается рост рынка AgeTech [18] и ожидается его удвоение. В Томской области проблема «потратить» деньги для большинства 55+ не стоит, больше половины тратят деньги на продукты питания и с возрастом такая тенденция только возрастает. Респонденты отметили, что вынуждены экономить по всем группам расходов, предложенным для оценки. В меньшей степени это касается расходов на ЖКХ, где 65 \% опрошенных выбрали вариант ответа «никогда не экономлю». Выявлена статистическая связь уровня дохода и практики экономии. Каждый второй, чей уровень душевого дохода составляет 6-12 тысяч рублей в месяц, отметили, что постоянно экономят на питании (48\%), еще $32 \%$ «время от времени/ постоянно» экономят на покупке одежды и обуви $(51 \%), 39 \%$ - время от времени. Именно в этой группе вдвое чаще экономят на лечении (36\% - постоянно, $39 \%$ - время от времени). В группе «высокодоходных» (более 26 тысяч рублей в месяц на человека) тех, кто постоянно экономит на питании и покупке одежды, заметно меньше (9-11 \%). Тем не менее практики обращения в институты поддержки за материальной помощью или получения социальных услуг не выявлено в массовом сегменте [19].

Определена статистически значимая связь между субъективными оценками респондентов удовлетворенности жизнью и их покупательной способностью (эмпирический уровень значимости меньше 0,05). Кроме того, установлено, что те, кто может позволить себе широкий набор товаров и услуг, включая возможности путешествовать, чаще выбирали ответ, что они полностью или частично удовлетворены жизнью в целом. Важным выводом является то, что на возможность путешествовать влияют не только финансовые ресурсы, но и социальные ограничения и физическое состояние [20]. Среди «недовольных» жизнью высокий процент тех, кто не может и не хотел бы иметь возможности путешествовать [21]. Данные результаты исследования по Томской области коррелируют с исследованиями из других стран [22]. 
Следовательно, покупательная способность влияет не только на формирование практики потребления, но и на удовлетворённость жизнью в целом. Вынужденное низкое материальное обеспечение развивает стратегии экономии, причем респонденты 55+ склонны предпочесть сэкономить на одежде или спорте и отдыхе, чем на питании и лечении. Всего 11 \% респондентов выбирали варианты экономии на услугах ЖКХ, что говорит о высокой финансовой дисциплине и социальной ответственности в старшем возрасте. Социальные институты поддержки пожилых людей сглаживают неравенство в доступе к товарам и услугам в старшем возрасте. Как показали данные опроса, становится доступнее страховая медицина, включая стоматологические услуги, растет удовлетворённость квалификацией врачей и качеством оказываемых услуг. Но говорить о том, что возрастная группа 55+ формирует новую практику потребления не приходится. Скорее, речь идет о гетерогенности потребительских предпочтений и необходимости дифференциации в зависимости от таких косвенных показателей (не только дохода), как удовлетворенность жизнью, возможности и желания путешествовать, наличие стратегии экономии, желание помогать детям и внукам и т. п. [23].

В социологическом исследовании 2021 г. наблюдается положительная динамика индикаторов по направлению трудовой занятости в сторону роста (+3 пп по отношению к данным предыдущих замеров). Рост занятости вызван, скорее всего, неудовлетворенностью пенсионного дохода, наблюдается отрицательная динамика по показателю пенсии как единственного источника дохода.

Тем не менее в социальной сфере востребованность социальных льгот крайне низкая, позитивной традиции не сформировалось, большая часть опрошенных не желает получать помощь от социальной службы. Социальная помощь от старшего поколения в основном направлена на ближний круг (детям/внукам 47 \% - каждый второй опрошенный - «помогает регулярно», 33 \% делает это от случая к случаю). Можно говорить о социальной включенности в пандемийное время старшего поколения, что подтверждают ранее полученные результаты МНОЛ ТУБПЛ ТПУ [17] приоритетных социальных ценностных установок старшего поколения и зависимости роста социальных ценностей с возрастом. Социальная помощь старшему поколению, в основном, оказывается ближним кругом родственников (82 \%). Снижается доля тех, кто считает, что не получает никакой социальной помощи. В пандемийный год наблюдается вовлеченность дальнего круга (соседи, знакомые) в помощь пожилым людям (15\%). Государственная социальная помощь оценивается крайне низко [24]: менее $18 \%$ респондентов отмечают государственные институты поддержки как ресурс для решения социальных вопросов. Удовлетворенность государственной социальной помощью показывает отрицательную динамику по всем направлениям помощи, что особенно заметно в сфере здоровья и материальной помощи [25].

В ноябре 2020 г. МНОЛ ТУБПЛ ТПУ было организовано проблемное интервью, чтобы выявить потребительские предпочтения в сфере потребления социальных услуг и проанализировать институциональный разрыв между социальными институтами как производителями социальных услуг и пожилыми людьми как потребителями. Осведомленность о наличии мер социальной помощи крайне низкая, половина ничего не смогли ответить по этому вопросу. Выявлена тенденция отсутствия интереса к институту социальной помощи, где находится потенциал развития рынка ухода за пожилыми людьми. 29 из 60 не пользуются никакими социальными льготами, 6 из 60 (все пенсионеры) считают, что не имеют права ни на какие льготы. Формируется ситуация институционального разрыва ожиданий субъектов социальной помощи и институтами поддержки. Не- 
смотря на мировые тренды «серебряного потребления» и высокую вовлеченность старшего поколения в цифровую реальность, запросы на дистанционные форматы социокультурной активности, спортивной не выявлены. Тем не менее 13 из 60 указывают на ухудшение качества жизни из-за снижения активности. Несмотря на все ожидания влияния социальной изоляции на старшие возрастные группы, 32 из 60 отмечают, что кроме «масок» ничего не изменилось. Это можно интерпретировать как отсутствие интереса к digital-форматам в силу неудовлетворенности базовых потребностей, т. к. цифровые сервисы в сфере доставки еды набирают популярность у 50+. Но мотивацией к такому поведению становится вовсе не доступность и повышение качества жизни, а тревога и потеря чувства безопасности при шопинге в условиях новой нормальности.

Потребительские потребности сильно зависят от материального достатка. Выявлено, что потребности в медицинских услугах напрямую коррелируют с низким материальным положением. Во всех группах высокая потребность социализации и отдыха (выше 50 \%), что говорит о ценностных установках старшего поколения, ориентированного на общение с ближним кругом. Пока нет четкого понимания, как выстраивать маркетинговые стратегии в отношении 50+, развивается рынок детских товаров (внукам). Крупные компании открывают исследовательские центры по здоровому старению, но пока устойчивого тренда на развитие этого сегмента как целевого нет, в том числе и на рынке России [26]. Люди в возрасте не особенно вовлечены в digital-жизнь, а это сейчас основной инструмент борьбы за внимание потребителей. Для томских пенсионеров (справедливо для России в целом) характерно взаимодействие в очереди к врачу или в банке, но никак даже не в социальном клубе по интересам [27]. Данные МНОЛ ТУБПЛ ТПУ с 2014 г. показывают, что привычки искать круг общения (внешний) по интересам не сформировано. Но есть и хорошие новости - доля вовлеченных в цифру растет, но практики использования цифровых технологий для поиска товаров и услуг не сформировано даже на уровне потребления медицинских и социальных услуг. В основном тенденция связана с социальной изоляцией и вынужденным цифровым общением с ближним кругом.

Выявлен определенный разрыв высоких потребностей наиболее уязвимой возрастной группы населения, реализующих стратегии экономии, и фактическим низким спросом на услуги институтов социальной поддержки.

Социальные институты являются производителями социальных услуг, в том числе и для старшего поколения. Следовательно, необходимо для целей эффективной реализации социальных услуг выстраивать маркетинговые коммуникации с целевой аудиторией, но данные опросов свидетельствуют о том, что существует какая-то проблема в движении информационного потока от производителей к целевой аудитории. Формулировка ценностного предложения строится на трех основных компонентах: отклике на желание целевой аудитории, позиционном отличии и формировании доверия. Формулу успешного ценностного предложения социальной услуги условно можно представить как трехкомпонентную модель (рис. 1).

Социальный институт в процессе дизайна функциональной ценности не должен забывать про эмоциональную и социальную ценность своей целевой аудитории [28]. Если мы говорим об институте социальной поддержки старшего поколения, то ценностное предложение социальной услуги раскладывается три компонента согласно базовой модели (рис. 1).

Во-первых, эмоциональная ценность (1) и ожидания целевой аудитории определенной поддержки на денежном и неденежном уровне. Дело не в стоимости социальной 
услуги, допустим, для благополучателя она может быть и бесплатной. Здесь важны аспекты ожиданий и ответа на сформулированные потребности и желания, некий отклик и эмпатия. Если продукт соответствует эмоциональным представлениям, то вероятность культурного восприятия социальной услуги выше. Результаты проведенного социологического исследования ценности институциональной поддержки (на примере функционирования института «социальный помощник») говорят о низком отклике респондентов на предоставляемые социальные услуги поддержки уязвимой возрастной группы, несмотря на выявленную неявную потребность в них. Осведомленность о наличии мер социальной поддержки и социальных льгот в возрастной группе 50+ очень низкая. Половина опрошенных не смогли ничего ответить по данному вопросу, но что примечательно - отмечается тенденция отсутствия интереса к институту социальной помощи. Те, кто что-то знает о льготах, чаще называли «жилищную субсидию/льготу за коммунальные платежи». (14) Известно, что эта субсидия выплачивается только тем пенсионерам, кто проживает/прописан в одиночестве. Выявлен стереотип - «оформить субсидию стало сложнее, чем раньше, нужно доказать, что у тебя маленькая зарплата». 29 опрошенных не пользуются никакими льготами, причем в основном так говорили пенсионеры. 15 человек ответили, что «ничего не знают о льготах и субсидиях», в этой группе были примерно в равных долях представлены пенсионеры и предпенсионеры. Еще 6 человек считают, что льготы им не положены (все пенсионеры). 4 человека (предпенсионеры) заявили, что им не нужны никакие льготы - дали бы лучше заработать. Таким образом, социальные услуги, предлагаемые социальными институтами поддержки старшего поколения, не отвечают на эмоциональные ожидания целевой аудитории. В такой ситуации не создается «осознания» важности и полезности предлагаемой социальной услуги.

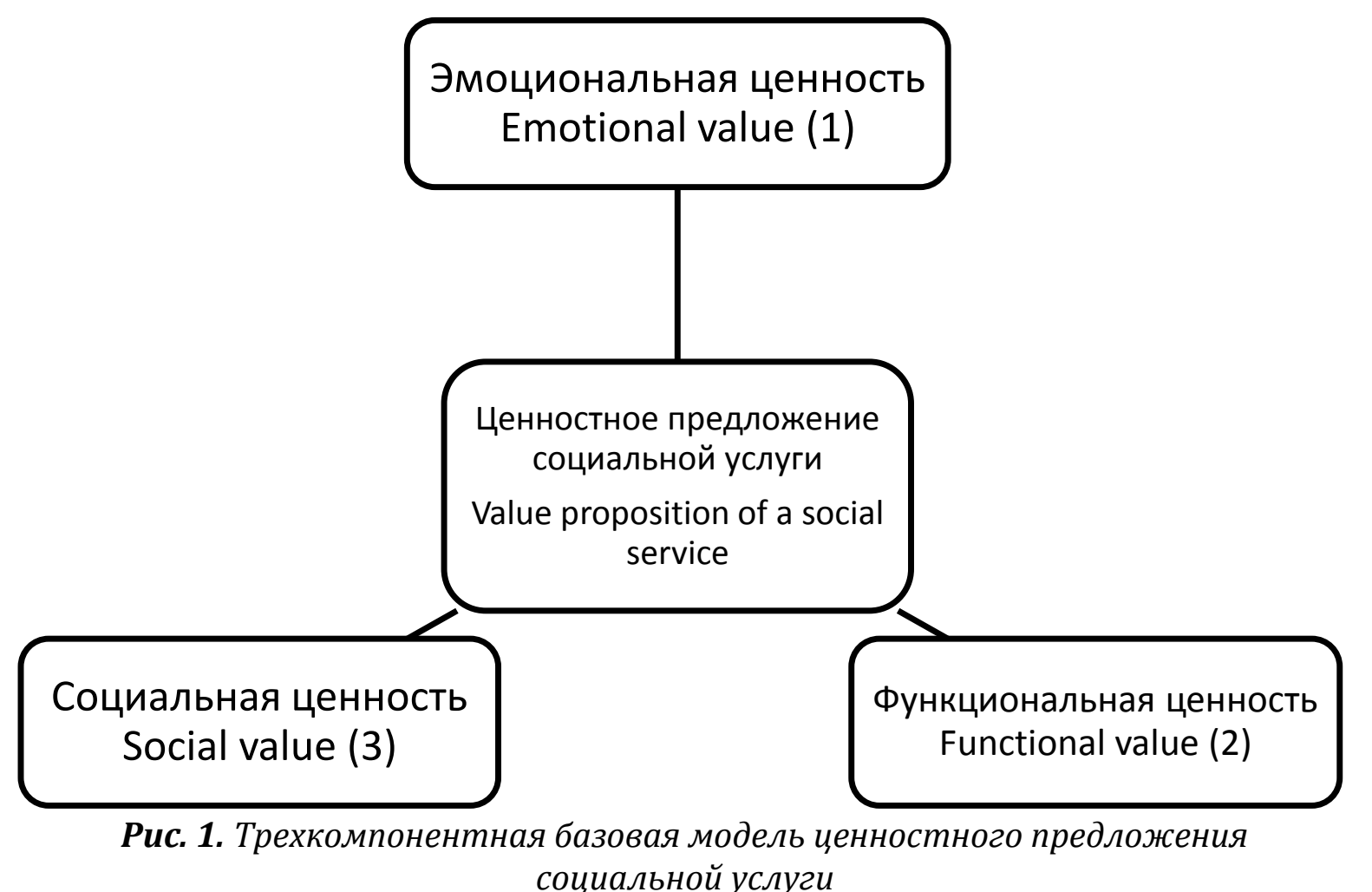

Fig. 1. Three-component basic model of the value proposition of a social service 
Во-вторых, важна функциональная ценность (2), т. е. новое решение социальной проблемы. С этой позиции социальные институты предлагают принципиально новый уровень решения острых социальных проблем, в том числе в сфере ухода за пожилыми людьми. Институт социального помощника многофункционален и определяется спектром социальных услуг от помощи по дому до ухода за тяжелобольными и лежачими пожилыми людьми. Безусловно, учитывая символический характер оплаты за социальные услуги на рынке, заменить институт государственной поддержки старшего поколения сложно, если не невозможно. Таким образом, функциональная ценность для старшего поколения социальных институтов поддержки, в частности института социального помощника, крайне высокая.

B-третьих, доверительные коммуникации и гарантии государства формируют социальную ценность (3) к институтам социальной поддержки. Реализуется возможность подтверждения предоставляемых социальных услуг государством, заключения официального договора социального обслуживания, получения дополнительных лицензий и результатов проверок контролирующими органами. Комплексные центры социального обслуживания в обязательном порядке публикуют отчеты о своей деятельности, вся информация открыта и находится в доступе офлайн и онлайн. Другое дело, что спрос на эту информацию невысокий, что подтверждает низкая осведомленность о наличии социальных услуг и поддержки населения. Тем не менее выявлена высокая степень доверия к государственным институтам социальной поддержки. В случае потребности в медицинской помощи наиболее распространённое мнение обратиться к врачам (специалистам), причем на основе полиса ОМС, т. е. получить услуги государственной социальной поддержки. Но что интересно, отмечается тенденция (каждый десятый из опрошенных) недоверия к системе здравоохранения, т. к. укоренился стереотип, что в условиях социальных ограничений учреждения здравоохранения стали недоступны. Дистанционные услуги медицинской помощи нельзя назвать новым трендом, осведомленность о наличии такой возможности крайне низкая, а факты обращения близки к статистической ошибке выборки. По направлению функционирования института здравоохранения выявлена проблема невозможности подтверждения гарантий качества предоставляемых услуг, что и формирует представление рискованности получения медицинской помощи в целом.

Таким образом, в модели ценностного предложения социальных услуг на примере института реализации социального помощника выявлен слабый отклик на эмоциональную потребность целевой аудитории, что формирует негативную субъективную оценку «ненужности» предлагаемого решения социальных проблем уязвимой старшей возрастной группы (рис. 2). Несмотря на неоспоримую функциональную ценность в форме помощи социального ассистента в бытовых делах от покупки продуктов и лекарств вплоть до ухода за лежачими пожилыми людьми, более половины опрошенных не осведомлены о наличии такого социального продукта. Государство содержит институты социальной поддержки, которые не находят потребительского спроса населения. Выявлено, что материальное положение старшей возрастной группы не является устойчивым, чтобы пренебрегать социальной помощью. Другими словами, неявная потребность в дополнительной социальной поддержке, безусловно, есть, но она не осознана самими пожилыми людьми. Примечательно, что в основном респонденты не допускают мысли о возможности часто обращаться за денежной помощью к кому-либо. Большая часть опрошенных (40 из 60) не имеет никаких сбережений, потому что просто не с чего откладывать (такой ответ дали 36 человек из 40). Так отвечали люди разного статуса, но преимущественно пенсионеры, как работающие, так и неработающие. В случае возникновения финансовых затруднений респонденты склонны в первую очередь обратиться к детям (но стараются 
этого не делать - 18 из 60), на втором месте - близкие родственники, на третьем месте банковский кредит или кредитная карта, т. к. другие способы неизвестны. 8 из 60 ответили, что им некуда обращаться и они надеются только на себя.

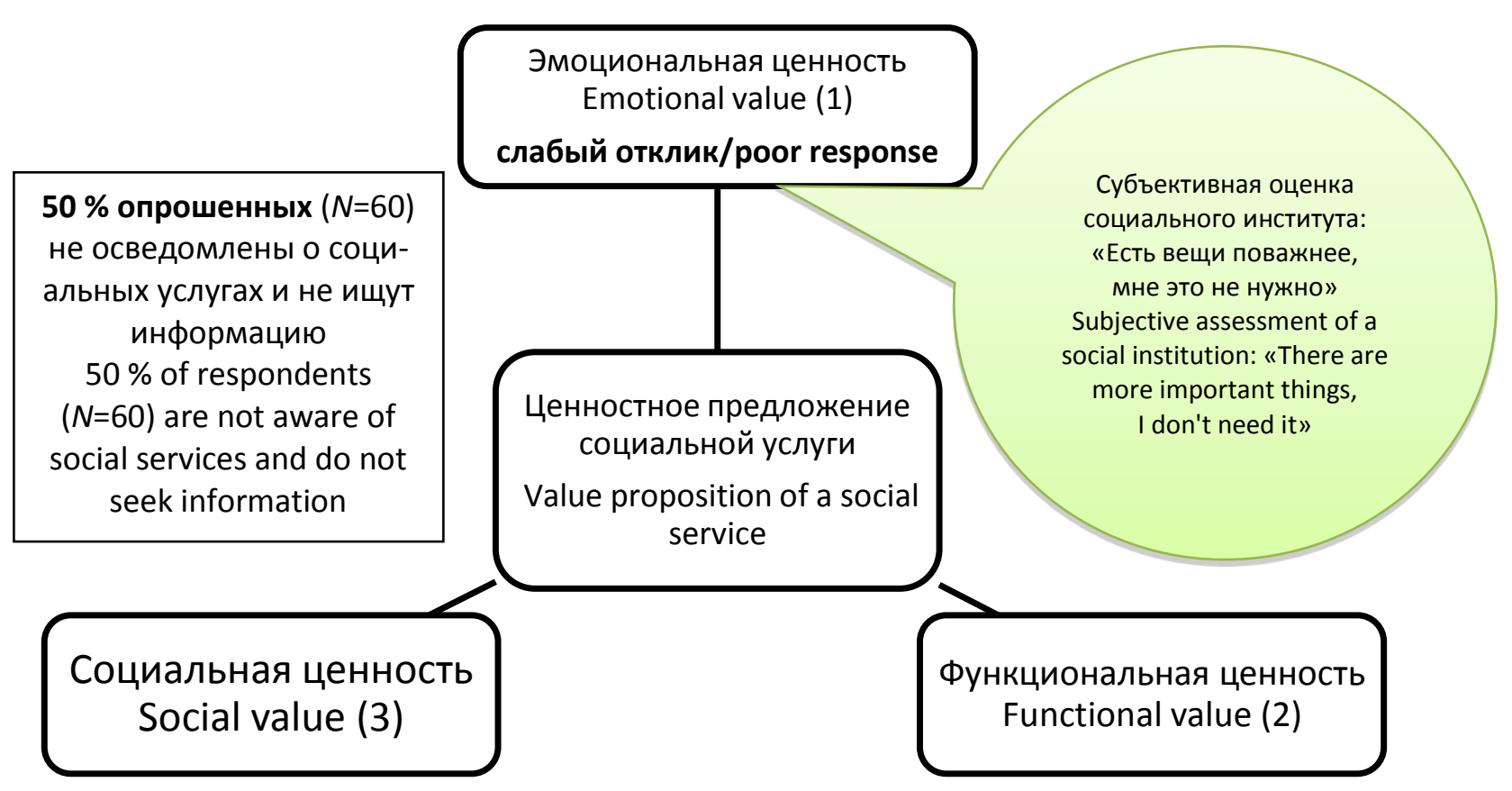

Puc. 2. Трехкомпонентная позитивная модель ценностного предложения социальной услуги на примере института социального помощника

Fig. 2. Three-component positive model of value proposition of a social service based on the example of the social assistant institution

Что касается изменения потребительского поведения, то респонденты склонны считать, что кроме жестких ограничительных защитных мер (ношение масок и социальной изоляции), «ничего особо не изменилось» (32). Каждый пятый отметил: «Активности не хватает, сидим дома - перестали ходить в кафе, заниматься спортом. Для меня это было очень важно. Мое качество жизни ухудшилось» (13). Тем не менее никто из респондентов не называл дистанционные или удаленные форматы активности, в том числе социокультурные или спортивные цифровые активности, которые пришли на замену привычному потреблению услуг. Выявлено, что в сфере потребления продуктов питания и товаров повседневного спроса наметился тренд на использование интернет-магазинов и услуг доставки продуктов питания. В основном, такое изменение потребительских практик связано с ощущениями тревоги и потери чувства безопасности при шопинге. Следовательно, можно говорить о том, что традиционные форматы предоставления социальных услуг остаются актуальными для старшего поколения. Развитие цифровых технологий предоставления социальных услуг не отвечает запросам респондентов. Соответственно, можно предложить новый дизайн ценностного предложения как стратегии развития социальных институтов и повышения их социально-экономической эффективности для преодоления институционального разрыва между производителями социальных услуг и целевой аудитории. Отвечая на запрос старшего поколения в аспекте изменения потребительского поведения следует учитывать запрос не на материальную помощь или бесплатность социальной услуги, а на повышение качества и уровня жизни в 
аспекте помощи поддержания активного образа жизни, сохраняя свои физические и социальные функции жизни и деятельности. Другими словами, в основе сильного эмоционального отклика социальным институтам следует учесть запрос на активное долголетие и поддержание не только утилитарных потребностей, но и психоэмоциональных и социальных потребностей, потребностей в самореализации.

\section{Заключение}

Практики потребления социальных услуг не выявлено, в частности материальной помощи. Несмотря на низкую обеспеченность 18 из 60 человек считают разумным обратиться к детям. Другие говорили о близких родственниках в целом и кредитах. Какие-то институты социальной помощи и поддержки не назывались вообще, хотя программы созданы, реализуются и имеются отчеты об их эффективности. Потенциал развития цифровых медицинских сервисов в старшей возрастной группе невысокий, т. к. не сформированы взаимоотношения между старшим поколением и новыми цифровыми сервисами, они их «не видят». Каждый десятый испытывает «недоверие» к системе здравоохранения из-за несформированности практики потребления дистанционной медицинской помощи. Осведомленность о наличии мер социальной помощи крайне низкая, половина ничего не смогли ответить по этому вопросу. Выявлена тенденция отсутствия интереса к институту социальной помощи, где находится потенциал развития рынка ухода за пожилыми людьми. В мире можно встретить примеры развития сферы размещения для пожилых людей, в частности сеть отелей «Марриот». В России укоренился культурный стереотип о «долге» заботы за старшими родственниками, тем самым рынок и его развитие сдерживаются. Хотя во всем мире наблюдается рост инвестиций в AgeTech и ожидается в скором времени удвоение рынка.

Выявлена проблема социальных институтов как производителей социальных услуг в аспекте взаимодействия с целевой аудиторией (пожилые люди). По нашим данным (ноябрь 2020) более половины не осведомлены о спектре социальных услуг и даже не интересуются. Стратегия потребления пожилых людей основана на экономии на базовых вещах (питании, лечении, одежде и обуви) говорит о низком качестве жизни и низком спросе на социально-культурные сервисы и экономику активного долголетия. Существует проблема доступности цифровых социальных услуг, несмотря на высокую цифровую вовлеченность старшего поколения ввиду отсутствия сформировавшейся практики потребления цифровых сервисов.

Субъективная оценка институтов социальной поддержки населения крайне низкая. Низкая эффективность социальных институтов связана с тем, что потребности целевой аудитории не осознаны в явном виде, а маркетинговые коммуникации не настроены на взаимодействие с эмоциональными потребностями старшего поколения и не соответствуют ожиданиям. Таким образом, ценность институциональной поддержки в глазах целевой аудитории невысокая, несмотря на развитый функционал и материальную поддержку, т. к. социальные сервисы либо бесплатные для пожилых людей, либо цена минимальна.

Таким образом, потенциал практик потребления в старшем возрасте высокий, текущее состояние показывает неразвитость практик потребления «серебряных» рынков. Потенциал инновационных практик в сфере социальной поддержки и ухода за пожилыми людьми высокий, но его реализация близка к статистической ошибке. Такую ситуацию можно объяснить институциональными разрывами между производителями услуг и сервисов и целевой аудиторией, которая не воспринимает «цифровые» коммуникации как инструмент взаимодействия. Выявлено высокое недоверие институтам поддержки и 
цифровым сервисам здравоохранения. Культурные барьеры мешают формированию новых практик потребления и росту рынка AgeTech. Решением видится выстраивание маркетинговых коммуникаций на основе ориентации на ценности старшего поколения и привычные источники информации.

Исследование выполнено при финансовой поддержке Российского научного фонда в рамках научноисследовательского проекта «Институты реализации ресурсного потенциала старшего поколения в экономике старения» (проект № 19-18-00300).

\section{СПИСОК ЛИТЕРАТУРЫ}

1. Troutman-Jordan M., Staples J. Successful aging from the viewpoint of older adults // Research and theory for nursing practice. - 2014. - V. 28. - № 1. - P. 87-104. DOI: 10.1891/1541-6577.28.1.87

2. Batat W. The coming out of the «new consumer». URL: https://www.researchgate.net/publication/ 254418704_The_coming_out_of_the_new_consumer (дата обращения: 03.02.2021).

3. Arnould E.J., Thompson C.J. Consumer Culture Theory (CCT): twenty years of research // Journal of Consumer Research. - 2005. - V. 31. - Iss. 4. - P. 868-882. DOI: https://doi.org/10.1086/426626

4. Csikszentmihalyi M. Mieux vivre en maitrisant votre énergie psychique. - Paris: Robert Laffont, 2005 - 192 p.

5. Holt D.B. How consumers consume: a typology of consumption practices // Journal of Consumer Research. 1995. - V. 22. - Iss. 1. - P. 1-16. DOI: https://doi.org/10.1086/209431

6. Nelson P. Information and consumer behavior // Journal of Political Economy. - 1970. - V. 78 (2). - P. $311-$ 329.

7. Разработка ценностных предложений / А. Остервальдер, И. Пинье, Г. Бернард, А. Смит. - М.: Альпина Паблишерс, 2014. - 321 с.

8. Huo C., Xiao G., Chen L. The crowding-out effect of elderly support expenditure on household consumption from the perspective of population aging: evidence from China // Frontiers of Business Research in China. 2021. - № 15 (1). DOI: 10.1186/s11782-021-00099-5

9. Shi M., Jiang Z., Qiu X. How ageing affects the expenditure of household consumption in China - evidence from Chinese social survey // Economic Theory and Economic Management. - 2019. - V. 4. - P. 62-79.

10. United Nations. World population prospects: the 2017 revision. United Nations Department of Economic and Social Affairs, Population Division (2017). URL: https://Esa.Un.Org (дата обращения: 03.02.2021).

11. Kim H.K., Lee S.-H. The effects of population aging on South Korea's economy: the National Transfer Accounts approach // The Journal of the Economics of Ageing. - 2021. - V. 20. - Article number 100340. DOI: https://doi.org/10.1016/j.jeoa.2021.100340

12. Support ratios and demographic dividends: Estimates for the World / A. Mason, R. Lee, M. Abrigo, S.H. Lee // United Nation Department of Economic and Social Affairs. - Technical Paper, 1, 2017. - 52 p. URL: https://www.un.org/en/development/desa/population/publications/pdf/technical/TP2017-1.pdf (accessed 05.04.2021).

13. Социально-экономическая статистика благополучия старшего поколения / Ф. Касати, Г.А. Барышева, Е.А. Монастырный, Л.И. Иванкина, И.А. Павлова, М.Л. Шинкеев, В.В. Спицын, Н.М. Панькова, И.В. Гуменников. - Томск: Интегральный переплет, 2016. - 264 с.

14. Фокина О.А. Трансформация потребительского поведения в низкообеспеченных социальных группах (на примере пенсионеров) в условиях институционализации сервиса // Современные исследования социальных проблем. URL: https://cyberleninka.ru/article/n/13981956.pdf (дата обращения 01.08.2021).

15. Reckwitz A. Toward a Theory of Social Practices // European J. of Social Theory. - 2002. - V. 5. - Iss. 2. P. 243-263.

16. Ечевская О.Г. Потребление и различие: социальные значения и практики потребительского поведения горожан. - Новосибирск: ИЭОПП СО РАН, 2011. - 160 с.

17. Официальный сайт Международной научно-образовательной лаборатории технологий улучшения пожилых людей Томского политехнического университета (сокращенно - MHOЛ ТБУПЛ TПУ). URL: https://tpu.ru/university/structure/department/view?id=7381 (дата обращения 06.08.2021).

18. Sixsmith A. COVID-19 and AgeTech // Quality in Ageing and Older Adults. - 2020. - V. 21. - Iss. 4 P. 247-252.

19. Atad O.I., Caspi D. Exercise and perceived quality of life among frail older adults // Quality in ageing and older adults. - 2020. - V. 21. - Iss. 1. - P. 29-38. 
20. Кучмаева О.В. Социальная активность пожилых россиян и перспективы реализации политики «активного старения» // Население и экономика. - 2018. - Т. 2. - № 4. - С. 47-84. DOI: https://doi.org/10.3897/popecon.2.e36060.

21. Иванкина Л.И., Аникина Е.А., Гуменников И.В. Обоснование модели влияния неравенства на субъективное благополучие пожилых людей // Социальные процессы в современном российском обществе: проблемы и перспективы: материалы IV Всероссийской научной конференции с международным участием. - Иркутск: Иркутский государственный университет, 2020. - С. 36-42.

22. Choung Y., Pak T.-Y., Chatterjee S. Consumption and life satisfaction: the Korean evidence // International Journal of Consumer Studies. - 2021. - № 45 (5). - P. 1007-1019. DOI: https://doiorg.ez.lib.tsu.ru/10.1111/ijcs.12620

23. Шерешева М.Ю., Валитова Л.А., Березка С.М. Потребительское поведение россиян возрастной категории 50+: пилотное исследование // Вестник Санкт-Петербургского университета. Менеджмент. 2017. - T. 16. - № 2. - С. 242-267.

24. Гужавина Т.А. Доверие как форма поддержки социальных институтов // SOCIETY AND SECURITY INSIGHTS. - 2019. - T. 2 - № 4. - C. 40-54.

25. Севастьянова Е.А. Институты поддержки социальных инноваций как инструмент активации гражданских инициатив // Теоретическая экономика. - 2019. - № 12 (60). - С. 87-97.

26. Bordone V., Arpino B., Rosina A. Forever young? An analysis of the factors influencing perceptions of ageing // Ageing \& society. - 2020. - V. 40. - Iss. 8. - P. 1669-1693.

27. How can technology support ageing in place in healthy older adults? A systematic review / A. Ollevier, G. Aguiar, M. Palomino, I.S. Simpelaere // Public health reviews. - 2020. - V. 41. - Iss. 1. DOI: 10.1186/s40985-020-00143-4

28. The needs of key-stakeholders for evaluating client's experienced quality of home care: a qualitative approach / R. Haex, T. Thoma-Lurken, S. Zwakhalen, A. Beurskens // Journal of patient-reported outcomes. - 2020. V. 1. - Iss. 2. - Article number 96. DOI: 10.1186/s41687-020-00260-3

Поступила 21.09.2021 г.. 
UDC 366.1-053.9

\title{
POTENTIAL FOR DEVELOPMENT OF CONSUMPTION PRACTICES IN OLDER AGE
}

\author{
Elena M. Rozhdestvenskaya, \\ elena.rojdestvenskaya@gmail.com \\ National Research Tomsk Polytechnic University, \\ 30, Lenin avenue, Tomsk, 634050, Russia
}

Elena M. Rozhdestvenskaya, Cand. Sc., leading researcher, National Research Tomsk Polytechnic University.

\begin{abstract}
Relevance. The work draws attention to the problems of the formation of consumption practices in old age as a fast-growing market segment (the growth rate according to the World Bank is $3 \%$ per year). The aim is to identify trends in consumer behavior in conditions of social restrictions and to determine the availability of new digital social services for the elderly. Methods. The data from sociological surveys conducted in November 2020 (N=60) and in March-April 2021 ( $N=400,55+)$ in the Tomsk region are used as an empirical base. As a result, we established that low consumption capacity affects the formation of consumption practices. The institutional gap has been revealed between high needs for social services and low demand for created social services. Conclusions. Consumption practices in older age are heterogeneous, a significant impact is exerted by a shortage of financial resources and values of helping the inner circle, strategies for saving on the most necessary are formed. The subjective assessment of respondents of social support institutions is extremely low. It is revealed that only in the field of social assistance new practices of remote interaction are being formed on the basis of digitalization of social services. The practice of remote treatment for material or medical care has not been identified. Trust in the institution of state support is extremely low, new digital services do not have a significant impact on maintaining the level and quality of life in conditions of social restrictions of the older age group.
\end{abstract}

Key words: Active aging, consumption practices, resource potential, economics of aging, institutional economics, well-being, social institutes.

The research was financially supported by the Rusian Science Foundation within scientific-research project "Institutes of implementation of resource potential of elderly generation in the economy of aging» (project no. 19-18-00300).

\section{REFERENCES}

1. Troutman-Jordan M., Staples J. Successful aging from the viewpoint of older adults. Research and theory for nursing practice, 2014, vol. 28, no. 1, pp. 87-104. DOI: 10.1891/1541-6577.28.1.87

2. Batat W. The coming out of the «new consumer». Available at: https://www.researchgate.net/publication/ 254418704_The_coming_out_of_the_new_consumer (accessed: 3 February 2021).

3. Arnould E.J., Thompson C.J. Consumer Culture Theory (CCT): twenty years of research. Journal of Consumer Research, 2005, vol. 31, Iss. 4, pp. 868-882. DOI: https://doi.org/10.1086/426626

4. Csikszentmihalyi M. Mieux vivre en maîtrisant votre énergie psychique [Live better by controlling your psychic energy]. Paris, Robert Laffont, 2005. 192 p.

5. Holt D.B. How consumers consume: a typology of consumption practices. Journal of Consumer Research, 1995, vol. 22, Iss. 1, pp. 1-16. DOI: https://doi.org/10.1086/209431

6. Nelson P. Information and consumer behavior. Journal of Political Economy, 1970, vol. 78 (2), pp. 311-329.

7. Ostervalder A., Pine I., Bernard G., Smith A. Razrabotka tsennostnykh predlozheniy [Development of value propositions]. Moscow, Alpina Pablishers Publ., 2014. 321 p.

8. Huo C., Xiao G., Chen L. The crowding-out effect of elderly support expenditure on household consumption from the perspective of population aging: Evidence from china. Frontiers of Business Research in China, 2021, no. 15 (1). DOI: 10.1186/s11782-021-00099-5

9. Shi M., Jiang Z., Qiu X. How ageing affects the expenditure of household consumption in China - evidence from Chinese social survey. Economic Theory and Economic Management, 2019, vol. 4, pp. 62-79.

10. United Nations. World population prospects: the 2017 revision. United Nations Department of Economic and Social Affairs, Population Division (2017). Available at: https://Esa.Un.Org (accessed 3 February 2021). 
11. Kim H.K., Lee S.-H. The effects of population aging on South Korea's economy: The National Transfer Accounts approach. The Journal of the Economics of Ageing, 2021, vol. 20, Article number 100340. DOI: https://doi.org/10.1016/j.jeoa.2021.100340

12. Mason A., Lee R., Abrigo M., Lee S.H. Support ratios and demographic dividends: Estimates for the World. United Nation Department of Economic and Social Affairs. Technical Paper, 1, 2017. 52 p. Available at: https://www.un.org/en/development/desa/population/publications/pdf/technical/TP2017-1.pdf (accessed 5 April 2021).

13. Kasati F., Barysheva G.A., Monastyrny E.A., Ivankina L.I., Pavlova I.A., Shinkeev M.L., Spitsyn V.V., Pankova N.M., Gumennikov I.V. Sotsialno-ekonomicheskaya statistika blagopoluchiya starshego pokoleniya [Socio-economic statistics of well-being of the older generation]. Tomsk, Integralny pereplet Publ., 2016. 264 p.

14. Fokina O.A. Transformatsiya potrebitelskogo povedeniya v nizkoobespechennykh sotsialnykh gruppakh (na primere pensionerov) $\mathrm{v}$ usloviyakh institutsionalizatsii servisa [Transformation of consumer behavior in lowincome social groups (on the example of pensioners) in the conditions of institutionalization of service]. Sovremennye issledovaniya sotsialnykh problem. Available at: https://cyberleninka.ru/article/n/ 13981956.pdf (accessed 1 August 2021).

15. Reckwitz A. Toward a Theory of Social Practices. European J. of Social Theory, 2002, vol. 5, Iss. 2, pp. 243263.

16. Echevskaya O.G. Potreblenie i razlichie: sotsialnye znacheniya i praktiki potrebitelskogo povedeniya gorozhan [Consumption and difference: social values and practices of consumer behavior of citizens]. Novosibirsk, IEOPP SO RAN Publ., 2011. 160 p.

17. Ofitsialny sayt Mezhdunarodnoy nauchno-obrazovatelnoy laboratorii tekhnologiy uluchsheniya pozhilykh lyudey Tomskogo politekhnicheskogo universiteta (sokrashchenno-MNOL TBUPL TPU) [Official site of the International Scientific and Educational Laboratory of Technologies for Improving the Elderly of the Tomsk Polytechnic University (abbreviated as MNOL TBUPL TPU)]. Available at: https://tpu.ru/university/structure/department/view?id=7381 (accessed 6 August 2021).

18. Sixsmith A. COVID-19 and AgeTech. Quality in Ageing and Older Adults, 2020, vol. 21, Iss. 4, pp. $247-252$.

19. Atad O.I., Caspi D. Exercise and perceived quality of life among frail older adults. Quality in ageing and older adults, 2020, vol. 21, Iss. 1, pp. 29-38.

20. Kuchmaeva O.V. Sotsialnaya aktivnost pozhilykh rossiyan i perspektivy realizatsii politiki «aktivnogo stareniya» [Social activity of elderly Russians and prospects for policy implementation «Active aging»]. Naselenie i ekonomika, 2018, vol. 2, no. 4, pp. 47-84. DOI: https://doi.org/10.3897/popecon.2.e36060.

21. Ivankina L.I., Anikina E.A., Gumennikov I.V. Obosnovanie modeli vliyaniya neravenstva na subektivnoe blagopoluchie pozhilykh lyudey [Substantiation of the model of the influence of inequality on the subjective well-being of older people]. Materialy IV Vserossiyskoy nauchnoy konferentsii $s$ mezhdunarodnym uchastiyem. Sotsialnye protsessy v sovremennom rossiyskom obshchestve: problemy i perspektivy [materials of the IV All-Russian scientific conference with international participation. Social processes in modern Russian society: problems and prospects]. Irkutsk, Irkutskiy gosudarstvenny universitet Publ., 2020. pp. 36-42.

22. Choung Y., Pak T.-Y., Chatterjee S. Consumption and life satisfaction: the Korean evidence. International Journal of Consumer Studies, 2021, no. 45 (5), pp. 1007-1019. DOI: https://doiorg.ez.lib.tsu.ru/10.1111/ijcs.12620

23. Sheresheva M.Yu., Valitova L.A., Berezka S.M. Potrebitelskoe povedenie rossiyan vozrastnoy kategorii 50+: pilotnoe issledovanie [Consumer behavior of Russians aged 50+: pilot study]. Vestnik Sankt-Peterburgskogo universiteta. Menedzhment, 2017, vol. 16, no. 2, pp. 242-267.

24. Guzhavina T.A. Doverie kak forma podderzhki sotsialnykh institutov [Trust as a form of support for social institutions]. Society and security insights, 2019, vol. 2, no. 4, pp. 40-54.

25. Sevastyanova E.A. Instituty podderzhki sotsialnykh innovatsiy kak instrument aktivatsii grazhdanskikh initsiativ [Institutions supporting social innovation as a tool for activating civic initiatives]. Teoreticheskaya ekonomika, 2019, no. 12 (60), pp. 87-97.

26. Bordone V., Arpino B., Rosina A. Forever young? An analysis of the factors influencing perceptions of ageing. Ageing \& society, 2020, vol. 40, Iss. 8, pp.1669-1693.

27. Ollevier A., Aguiar G., Palomino M., Simpelaere I.S. How can technology support ageing in place in healthy older adults? A systematic review. Public health reviews, 2020, vol. 41, Iss. 1. DOI: 10.1186/s40985-02000143-4

28. Haex R., Thoma-Lurken T., Zwakhalen S., Beurskens A. The needs of key-stakeholders for evaluating client's experienced quality of home care: a qualitative approach. Journal of patient-reported outcomes, 2020, vol. 1, Iss. 2, Article number 96. DOI: 10.1186/s41687-020-00260-3

Received: 21 September 2021. 